\title{
Targeting Interleukin(IL)-30/IL-27p28 signaling in cancer stem-like cells and host environment synergistically inhibits prostate cancer growth and improves survival
}

\author{
Carlo Sorrentino ${ }^{1,2}$, Zhinan Yin ${ }^{3}$, Stefania Ciummo ${ }^{1,2}$, Paola Lanuti ${ }^{1}$, Li-Fan Lu' ${ }^{4}$, Marco Marchisio ${ }^{1}$,
} Matteo Bellone ${ }^{5}$ and Emma Di Carlo ${ }^{1,2^{*}}$ (D)

\begin{abstract}
Background: Interleukin(IL)-30/IL-27p28 production by Prostate Cancer (PC) Stem-Like Cells (SLCs) has proven, in murine models, to be critical to tumor onset and progression. In PC patients, IL-30 expression by leukocytes infiltrating PC and draining lymph nodes correlates with advanced disease grade and stage. Here, we set out to dissect the role of host immune cell-derived IL-30 in PC growth and patient outcome.

Methods: PC-SLCS were implanted in wild type (WT) and IL-30 conditional knockout (IL-30KO) mice. Histopathological and cytofluorimetric analyses of murine tumors and lymphoid tissues prompted analyses of patients' PC samples and follow-ups.
\end{abstract}

Results: Implantation of PC-SLCs in IL-30KO mice, gave rise to slow growing tumors characterized by apoptotic events associated with $C D 4^{+} T$ lymphocyte infiltrates and lack of $\mathrm{CD}^{+}{ }^{+} \mathrm{Foxp}^{+} \mathrm{T}$ regulatory cells (Tregs). IL-30 knockdown in PCSLCs reduced cancer cell proliferation, vascularization and intra-tumoral Indoleamine 2,3-Dioxygenase $(\text { IDO })^{+} \mathrm{CD} 11 \mathrm{~b}^{+} \mathrm{Gr}$ $1^{+}$myeloid-derived cells (MDCs) and led to a significant delay in tumor growth and increase in survival. IL-30-silenced tumors developed in IL-30KO mice, IL-30 ${ }^{-/-}$tumors, lacked vascular supply and displayed frequent apoptotic cancer cells entrapped by perforin ${ }^{+}$TRAIL $^{+} C D 3^{+}$Tlymphocytes, most of which had a CD4 ${ }^{+} T$ phenotype, whereas IL-

$10^{+}$TGF $\beta^{+}$Foxp $3^{+}$Tregs were lacking. IL-30 silencing in PC-SLCs prevented lung metastasis in 73\% of tumor-bearing WT mice and up to $80 \%$ in tumor-bearing IL-30KO mice.

In patients with high-grade and locally advanced $\mathrm{PC}$, those with IL-30-/- tumors, showed distinct intra-tumoral cytotoxic granule-associated RNA binding protein $(T I A-1)^{+} C D 4^{+}$Tlymphocyte infiltrate, rare Foxp3 ${ }^{+}$Tregs and a lower biochemical recurrence rate compared to patients with $\mathrm{IL}-30^{+/+}$tumors in which IL-30 is expressed in both tumor cells and infiltrating leukocytes.

(Continued on next page)

\footnotetext{
* Correspondence: edicarlo@unich.it

${ }^{1}$ Department of Medicine and Sciences of Aging, G. d'Annunzio University of

Chieti-Pescara, Via L. Polacchi 11, 66100 Chieti, Italy

${ }^{2}$ Anatomic Pathology and Immuno-Oncology Unit, Center for Advanced

Studies and Technology (CAST), G. d'Annunzio University of Chieti-Pescara,

Chieti, Italy

Full list of author information is available at the end of the article
}

(c) The Author(s). 2019 Open Access This article is distributed under the terms of the Creative Commons Attribution 4.0 International License (http://creativecommons.org/licenses/by/4.0/), which permits unrestricted use, distribution, and reproduction in any medium, provided you give appropriate credit to the original author(s) and the source, provide a link to the Creative Commons license, and indicate if changes were made. The Creative Commons Public Domain Dedication waiver (http://creativecommons.org/publicdomain/zero/1.0/) applies to the data made available in this article, unless otherwise stated. 
(Continued from previous page)

Conclusion: The lack of host leukocyte-derived IL-30 inhibits Tregs expansion, promotes intra-tumoral infiltration of CD4 ${ }^{+} \mathrm{T}$ lymphocytes and cancer cell apoptosis. Concomitant lack of MDC influx, obtained by IL-30 silencing in PC-SLCS, boosts cytotoxic T lymphocyte activation and cancer cell apoptosis resulting in a synergistic tumor suppression with the prospective benefit of better survival for patients with advanced disease.

Keywords: Interleukin-30, Tumor microenvironment, Prostate Cancer Stem-Like Cells, Treg cells, Immunohistochemistry

\section{Background}

Prostate cancer (PC) is the most common non-cutaneous malignant neoplasm in men [1]. As its incidence increases with age, an increase in the number of new cases is expected in the near future due to the aging of the population [2]. Mortality for PC is mainly due to metastatic disease, for which there is no effective cure. The definition of the molecular mechanisms driving this process is crucial to identify the right therapeutic targets.

Originally identified as the p28 subunit of the heterodimeric cytokine Interleukin(IL)-27 [3, 4], and found to suppress the antitumor effects of IL-27 in colon cancer [5], IL-30 is emerging as a new and intriguing factor that may condition PC onset and progression [6-8]. It is produced by tumor-infiltrating leukocytes, mostly myeloid derived cells (MDCs), in approximately $77 \%$ of metastatic PC. Expression of IL-30 in PC and leukocytes infiltrating tumor and draining lymph nodes is associated with poorly differentiated high grade and stage of disease [6]. High levels of IL-30 in MDCs of tumor-draining lymph nodes from breast cancer patients have also proven to be an independent predictor of poor prognosis [9], thus suggesting the involvement of IL-30, produced by the host's immune cells, in conditioning tumor behavior and patient outcome.

Our most recent study revealed that PC Stem-Like Cells (PC-SLCs), which are believed to be responsible for tumor initiation, progression and treatment resistance [10, 11], are a significant source of IL-30 in PC [8]. IL-30 promotes PC-SLC viability, self-renewal ability, tumorigenic and metastatic potential, as revealed by using a fully immunocompetent orthotopic murine model and it regulates, essentially via STAT1 and STAT3 signaling, a range of proinflammatory and chemokine/chemokine-receptor genes that promote tumor growth [8]. IL-30 knockdown in PCSLCs hinders their engraftment and dramatically compromises tumor onset and progression. However, beyond IL30 produced by cancer cells and acting in autocrine and paracrine loops, the function of endogenous IL-30 released by tumor- and draining lymph node-infiltrating leukocytes (ILK), which has been associated with a worse prognosis, remains to be addressed.

In this study, IL-30/IL-27p28 conditional knockout mice were used as recipients for PC-SLC implantation and tumor growth to determine whether host immune cell-derived IL-30 is essential to PC progression and therefore if it should be considered in planning an effective cytokine targeted immunotherapy to treat or prevent the metastatic disease.

\section{Methods}

\section{Cell cultures}

Murine Prostatic Intraepithelial Neoplasia (PIN)-derived Stem-Like Cells (PIN-SCs) were isolated from B6 TRAMP mice [12] and characterized in refs. [13, 14].

For our purposes, we used, in addition to wild type PIN-SCs, two of the cell lines stably silenced for the IL30 gene (by using short hairpin, sh, RNA Hush GFPtagged lentiviral vectors from Origene), which exhibited the highest knockdown efficiency (IL-30shPIN-SCs clone D: $89 \%$ and clone B: $82 \%$ ), and related control cells transfected with non-effective scrambled shRNA, namely shPIN-SCs, generated in our laboratory and previously described [8]. Cell lines were authenticated by means of cell surface staining for characteristic markers, as described [13, 14], by in vitro tests (cell proliferation and sphere formation) and ELISA assay for IL-30 (mIL27p28/IL-30 Quantikine ELISA kit, R\&D) as described [8]. Since the two IL-30-silenced cell lines we used demonstrated similar biological behavior in vitro [8] and in vivo, only results from Clone D are shown.

Cells were cultured using serum-free medium (SFM), which consisted of DMEM:F12 (1:1), GlutaMAX-I supplement (Invitrogen), $50 \mathrm{ng} / \mathrm{ml}$ heparin (Sigma-Aldrich), 20 $\mathrm{ng} / \mathrm{ml}$ EGF, and $10 \mathrm{ng} / \mathrm{ml} \beta \mathrm{FGF}$ (R\&D), as described [14]. Mycoplasma contamination was excluded by using the MycoAlert $^{\mathrm{T}}$ PLUS Mycoplasma Detection Kit (Lonza).

\section{Mouse studies}

The IL-27p28 conditional knockout mouse strain (EIIa$\mathrm{p} 28^{\mathrm{f} / \mathrm{f}}$ ), that has been described by Zhang et al. [15], was kindly provided by Prof. Yin Z. (Jinan University, Guangdong, China) and Prof. Lu L.F. (University of California, San Diego, CA, USA), whereas Wild Type C57BL/6 J (WT) mice were purchased from Envigo. The genotyping of EIIa$\mathrm{p} 28^{\mathrm{f} / \mathrm{f}}$ mice was performed via polymerase chain reaction (PCR), using the following primers (Sigma-Aldrich): TCCC TTCCAGGACCATACTGCTAA (forward) and ACCC AAACACAGGCCAGTACTCTA (reverse) to detect the WT band (252 bp); CTGCAGCCAAGCTATCGAATTCCT (forward) and TGCATCACCACACTTGGCGTACTA 
(reverse) to detect the null band (230 bp). The PCR procedures were carried out on an MJ Mini Gradient Thermal Cycler (Bio-Rad) under the following conditions: $95^{\circ} \mathrm{C}$ for $4 \mathrm{~min}$, followed by 35 amplification cycles (denaturation at $94{ }^{\circ} \mathrm{C}$ for $45 \mathrm{~s}$, annealing at $66^{\circ} \mathrm{C}$ for $45 \mathrm{~s}$ and extension at $72{ }^{\circ} \mathrm{C}$ for $\left.1 \mathrm{~min}\right)$. The PCR products were separated on a $2 \%$ agarose gel stained with ethidium bromide and the DNA bands were visualized with a Transilluminator 2000 (BioRad). The p28 knockout efficiency was confirmed by quantitative real-time PCR, on peripheral blood leukocytes, and by ELISA, on serum samples, using the mIL-27p28/IL-30 Quantikine ELISA kit (R\&D; detection sensitivity $4.27 \mathrm{pg}$ / $\mathrm{ml}$ ) according to manufacturer's instructions.

In addition to WT mice, we used B6 EIIa-cre mice (Jackson Laboratory) and $\mathrm{p} 28^{\mathrm{f} / \mathrm{f}}$ mice (carrying two LoxP sites flanking $p 28$ exons 2, 3 and 4) as controls, because Cre expression and $p 28$ floxing could contribute, by themselves, to the mouse phenotype.

Groups of 45 mice were subcutaneously (sc) injected with 1 X $10^{5}$ PIN-SCs, shPIN-SCs or IL-30shPIN-SCs and monitored 2 times per week. Tumors were measured with calipers as soon as they were palpable and until evidence of suffering was observed. Then, mice were euthanized and tumors and other organs were collected for morphological and molecular analyses.

- Power calculation - Since a one-sided log rank test, with an overall sample size of 30 mice per group, achieves an $90 \%$ power, at a 0.05 significance level, to detect a difference of $30 \%$ in tumor growth, 30 mice per group were kept until evidence of suffering was observed. Fifteen mice, from each group, were sacrificed for histopathological studies, at key time points (groups of 3) based on tumor growth and progression rate.

\section{Flow cytometry}

Spleens from WT or EIIa-p28 $8^{\mathrm{f} / \mathrm{f}}$ mice (sc injected or not with PIN-SCs) were excised and cut into small pieces that were crushed through a Corning ${ }^{\circledR}$ cell strainer (size $\left.40 \mu \mathrm{m}\right)$ using a syringe plunger. Subsequently, the cells were resuspended in $2 \mathrm{ml}$ of pre-warmed lysing solution (BD Biosciences) and incubated at $37^{\circ} \mathrm{C}$ in a water bath for $2 \mathrm{~min}$. To assess phenotype markers, PIN-SCs were harvested and mechanically dissociated into a single cell suspension.

Then, the cells were pelleted, resuspended in PBS and incubated for $30 \mathrm{~min}$, at $4{ }^{\circ} \mathrm{C}$, with the antibodies (Abs) listed in Additional file 1: Table S1 at a concentration of $0.25 \mu \mathrm{g} / 100 \mu \mathrm{l}$. Acquisition was performed using a BD FACSCanto II instrument and the data were analyzed using FlowJo software. Dead cells were excluded by 7AAD staining. All experiments were performed in triplicate.

\section{Patients and samples}

Prostate tissue samples were obtained from patients who underwent radical prostatectomy for PC, between 2009 and 2013, at the S.S. Annunziata Hospital (Chieti, Italy). PC patients, ages 60-70, had not received immunosuppressive treatments, hormone- or radio-therapy [16] and were free from immune system diseases. They were followed-up for at least 5 years after prostatectomy.

Biochemical recurrence (BCR) was defined as a PSA value $>0.2 \mathrm{ng} / \mathrm{ml}$ after prostatectomy, confirmed by another measurement after 4 weeks [17].

Clinic-pathological stages were determined according to the seventh edition of the TNM classification of malignant tumors [18] and tumor grade was assessed according to the Gleason scoring system from the prostate biopsies [19].

For this study, we analyzed n.112 PC samples obtained from patients at Stage III (pT3N0M0, with negative surgical margins), with Gleason score of 8-10. After staining for IL-30, we selected and then analyzed only PC specimens that were found (i) to express IL-30 in both PC cells and ILK (referred to as IL- $30{ }^{\mathrm{Pos}} \mathrm{PC} ; n$. $25)$ or (ii) to lack IL-30 expression in both PC cells and ILK (referred to as IL-30 ${ }^{\mathrm{Neg}} \mathrm{PC} ; n$. 59), according to the criteria that we defined previously [6] and describe below.

IL-30 expression in neoplastic cells, of human PC specimens, was evaluated using the following criteria, that we previously applied [6] and that are based on 1) the widening of the staining expressed as the percentage of tumor stained, i.e.: $<50 \%$, between 50 and $70 \%$, and > $70 \%$, and 2) the strength of the staining: defined as absent $(-)$, slight $( \pm)$, distinct $(+)$ or strong $(++)$.

Thus, IL-30 immunostaining was defined as:

- positive, when a) the widening was $>70 \%$ and its strength ranged from slight $( \pm)$ to strong $(++)$, or b) the widening was between 50 and $70 \%$ and its strength ranged from distinct $(+)$ to strong $(++)$;

- weakly positive, when a) the widening was between 50 and $70 \%$ and its strength was slight $( \pm)$, or b) the widening was equal to $50 \%$ and its strength ranged from slight $( \pm)$ to strong $(++)$;

- negative when the widening was $<50 \%$ and its strength was slight $( \pm)$ to absent $(-)$.

ILK expression of IL-30 in human PC samples was evaluated using the following score, based on 1) the percentage of leukocyte expressing the cytokine, i.e. $<50 \%$, between 50 and $70 \%$, and $>70 \%$, and 2) the strength of the cytokine staining, that was defined as absent $(-)$, scarce $( \pm)$, distinct $(+)$ or strong $(++)$.

Thus, IL-30 expression by ILK was defined as:

- strong, when a) the staining involved more than 70\% of leukocytes and its strength ranged from scarce $( \pm)$ to strong $(++)$, or b) the percentage of positively stained leukocytes was between 50 and $70 \%$ and the 
strength of the staining ranged from distinct $(+)$ to strong $(++)$;

- distinct, when a) the staining involved $>50 \%$ and $\leq$ $70 \%$ of leukocytes and its strength was scarce $( \pm)$, or b) the staining involved $50 \%$ of leukocytes and its strength ranged from scarce $( \pm)$ to strong $(++)$;

- scanty, when the staining involved $<50 \%$ of leukocytes and its strength ranged from scarce $( \pm)$ to absent $(-)$.

Therefore, PC samples with positive and strong IL-30 expression were classified as IL- $30^{\mathrm{Pos}} \mathrm{PC}$, whereas PC samples with negative and scanty IL-30 expression were classified as IL- $30^{\mathrm{Neg}} \mathrm{PC}$.

Immunostained sections were examined by two pathologists in a blind fashion, with very good agreement ( $\mathrm{K}$ value $=0.89$ and 0.78 for evaluation of IL-30 staining in PC cells and ILK, respectively).

\section{Histopathology, immunohistochemistry, confocal microscopy and TUNEL staining}

For histology and immunohistochemistry, human PC specimens and half of each murine tissue sample were fixed in $4 \%$ formalin, embedded in paraffin and sectioned at $4 \mu \mathrm{m}$ for hematoxylin and eosin (H\&E) or immunostaining. For double immunofluorescent stainings, the other half of the murine sample was embedded in Killik frozen section medium (Bio-Optica), snap frozen in liquid nitrogen and preserved at $-80^{\circ} \mathrm{C}$.

Single, double (CD11b/Gr-1, CD11b/IDO, IL-30/F4/80, Foxp3/CD4, Foxp3/IL-10, Foxp3/TGF 3 , CD3/perforin, caspase-3 (Casp3)/CD3, CD4/TIA-1, F4/80/IFN $\gamma$ and $\mathrm{CD} 3 / \mathrm{IFN} \gamma$ ) or triple (IL-30/CD11b/Gr-1) immunostainings on formalin-fixed, paraffin-embedded mouse and human tissue sections, were performed using the Abs listed in Additional file 1: Table S2, as reported [6, 8, 20].

Double immunofluorescent stainings (CD3/TRAIL and $\mathrm{CD} 4 / \mathrm{FasL}$ ) were performed on frozen sections, as described [20], and examined using a Zeiss LSM 510 Meta laser scanning confocal microscope (Zeiss).

Since formaldehyde denatures tissue macromolecules, thus making some tissue antigens inaccessible to the primary Abs (antigen masking), when necessary, we performed "antigen unmasking" by heat induced epitope retrieval. Sensitivity and specificity of the stainings were confirmed by testing serial dilutions of each $\mathrm{Ab}$ on appropriate positive control tissues, listed in Additional file 1: Table S2, whereas sections incubated with non-immune sera or diluent were used as negative controls. Rodent Block (Biocare Medical) was used to minimize endogenous Ig staining when using mouse primary Abs on mouse tissue.

TUNEL staining was performed with the ApopTag Peroxidase In Situ Apoptosis Detection Kit (Merck Millipore) following manufacturer's instructions, using spleen sections as positive control.

Proliferation index, microvessel and cell counts were assessed by light microscopy, at $\times 400$, in an $85431.59 \mu \mathrm{m}^{2}$ field, on single immunostained sections, with Qwin image analysis software (version 2.7), which has the following highly reproducible steps: 1) image acquisition; 2) conversion of RGB image (true colors) to binary image (black and white);3) filtering to remove noise; 4) counting of immunostained cells or measurement of positively stained area.

For morphometric analyses on mouse tissue samples, six-eight high-power fields were evaluated for each section and three sections per sample were analyzed. Results are expressed as mean $\pm \mathrm{SD}$ of positive cells per field (F4/80, CD11b/Gr-1, Foxp3/CD4, CD3, NKp46, Ly-6G, CD4, CD8) or mean percentage of positive cells/number of total cells (Sca-1, PCNA, TUNEL, caspase-3, perforin).

$\mathrm{CD}^{+}$and Foxp $3^{+}$cell counts, on human PC samples, were performed by adding together the positive cells scattered in fields randomly chosen within neoplastic areas and values are represented as the mean \pm SD of positive cells/field. Eight to 12 high-power fields were examined for each section and 2 sections per sample were evaluated, as reported [20].

\section{Statistical analysis}

For in vitro and in vivo studies, between-group differences were assessed by Student's $t$-test and ANOVA (followed by Tukey HSD test). Between-group differences in sphere-forming potential were evaluated by ELDA ( $\mathrm{Hu}$ et al. J Immunol Methods 2009). Survival curves were constructed using the Kaplan-Meier method and survival differences were analyzed by the log-rank test. Follow-up time was 60 months. All statistical tests were evaluated at an $\alpha$ level of 0.05, using Stata version 13 (Stata Corp).

\section{Results}

The lack of IL-30 in PC-SLCs and host environment synergistically inhibits tumor growth, reduces lung metastasis and prolongs host survival

The hypothesis of a patho-biological role for host-derived IL-30 in tumor progression was tested by using p28 conditional knockout, EIIa-p28 $8^{\mathrm{f} / \mathrm{f}}$ mice (C57BL/6 J background), hereinafter referred to as IL-30KO mice. These mice were sc injected with PC-SLCs isolated from Prostatic Intraepithelial Neoplasia (PIN), spontaneously arisen in B6 TRAMP mice (hemizygous for the rat probasin $\mathrm{Pb}$-SV40gp6 large $\mathrm{T}$ antigen transgene in a C57BL/6 J background, refs [12-14]. These cells, namely PIN-SCs [8] are characterized by a Sca$1^{+} \mathrm{CD} 133^{+} \mathrm{CD} 44^{\mathrm{hi}} \alpha 2 \beta 1^{\text {hi }}$ phenotype and lack of CD45 and CD31 markers [13], as validated by flow cytometry (Fig. 1A), to exclude the use of differentiated cells. PIN- 

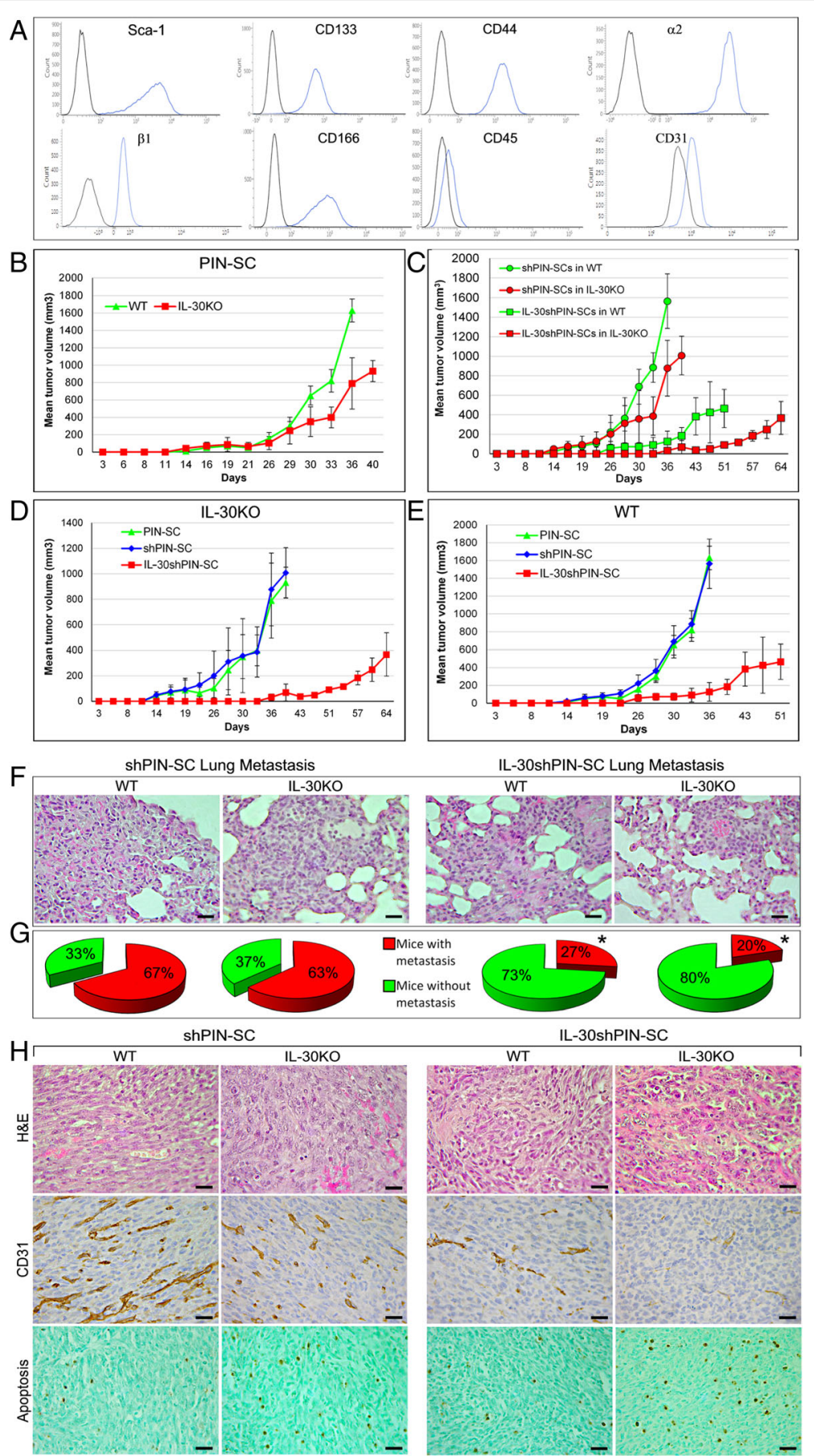

Fig. 1 (See legend on next page.) 
(See figure on previous page.)

Fig. 1 Characteristics of the growth and progression of tumors developed after sc implantation of IL-30-silenced PIN-SCs in WT and IL-30KO mice a Flow cytometric profiling of phenotype markers expressed by PIN-SCs. Blue profiles illustrate the expression of specific markers, while black profiles represent isotype controls. Each panel is representative of three independent experiments. b Mean volume of tumors developed after implantation of PIN-SCs in WT or in IL-30KO mice. Student's t-test: $p<0.0001$ versus WT mice. Results from B6 Ella-cre mice and p2 $8^{\mathrm{f} / \mathrm{f}}$ mice are not different from those obtained in WT mice (Fisher Exact Probability Test: $p>0.99$ ). c Mean volume of tumors developed after implantation of shPIN-SCs or IL-30shPIN-SCs in WT or in IL-30KO mice. Student's t-test: $p<0.001$ (shPIN-SCs or IL-30shPIN-SCs in IL-30KO mice versus WT mice). Results from B6 Ella-cre mice and p28 $8^{\mathrm{f} / \mathrm{f}}$ mice are not different from those obtained in WT mice (Fisher Exact Probability Test: $p>0.99$ ). $\mathbf{d}$ Mean volume of tumors developed after implantation of PIN-SCS, shPIN-SCs or IL-30shPIN-SCs in IL-30KO mice. ANOVA: $p<0.001$. Tukey's HSD test: $p<$ 0.01 versus both controls. e Mean volume of tumors developed after implantation of PIN-SCs, shPIN-SCs or IL-30shPIN-SCs in WT mice. ANOVA: $p<0.01$. Tukey's HSD test: $p<0.01$ versus both controls. $\mathbf{f}$ H\&E stained sections of lung metastasis spontaneously developed in WT and in IL-30KO mice bearing ShPIN-SC or IL-30shPIN-SC tumors. Magnification: $\times 400$. Scale bars: $30 \mu \mathrm{m}$. g Percentage of lung metastasis spontaneously developed in WT and in IL-30KO mice bearing shPIN-SC or IL-30shPIN-SC tumors. *Fisher's exact test: $p<0.01$ versus shPIN-SC tumors in both WT and IL-30KO mice. $\mathbf{h}$ Histologic (H\&E) and immunohistochemical features of tumors developed after sc implantation of shPIN-SCs or IL-30shPINSCs in WT and in IL-30KO mice. Magnification: $\times 400$. Scale bars: $30 \mu \mathrm{m}$

SCs have endless self-renewal ability, PC-SLC-specific molecular signature [14] and tumor generating capability at a very low cell number in immune-competent host [8]. Furthermore, they express both IL-30 receptor (R) chains, gp130 and IL-6R $\alpha$ [8], and constitutively express and release IL-30, whereas they do not produce neither EBI3, nor the IL-27 heterodimer [8].

Eighteen days after their subcutaneous sc implantation, PIN-SCs $\left(1 \times 10^{5}\right.$ cells for a $100 \%$ tumor take; ref. [8] gave rise to tumors that grew significantly slower in IL-30KO (IL-30 $0^{+/}$tumors) than in WT (IL-30 $0^{+/+}$tumors) mice. Their mean volume (MTV) was significantly lower than that of tumors developed in WT mice (MTV; $789.76 \pm 295.17$ versus $1629.56 \pm 132.69 \mathrm{~mm}^{3}$; student's t-test: $p<0.0001$; Fig. 1B).

Since the suppression of IL-30 production by PIN-SCs, via shRNA silencing (IL-30shPIN-SC cells), substantially hindered tumor onset and progression in congenic host [8], we wondered whether the concomitant lack of hostderived IL-30 might strengthen these effects.

Implantation of IL-30shPIN-SCs in IL-30KO mice gave rise to small IL-30 ${ }^{-1}$ tumors with a MTV $(91.22 \pm$ $6.75 \mathrm{~mm}^{3}$ ) that was not only considerably lower than that of tumors developed in WT mice (IL-30 ${ }^{-1+}$ tumors) (MTV: $464.39 \pm 196.41 \mathrm{~mm}^{3}$ ) (Student's t-test: $p<$ 0.001 ) (Fig. 1C), but that was also drastically reduced $(p<0.01)$ when compared to the MTV of PIN-SC- and shPIN-SC-tumors $\left(931.77 \pm 120.70 \mathrm{~mm}^{3}\right.$ and $1007.43 \pm$ $197.69 \mathrm{~mm}^{3}$, respectively) developed in IL-30KO mice (Fig. 1D). Of note, the survival of IL-30KO mice bearing IL-30shPIN-SC tumors was considerably longer than that of WT mice bearing IL-30shPIN-SC tumors (64 versus 51 days) (Log-rank test: $p=0.047430$ ) (Fig. 1C). The latter, in turn, survived longer than WT mice bearing PIN-SC or shPIN-SC tumors, which had to be sacrificed within 36 days (Chi-square test: $p<0.0001$ ) (Fig.1E). Thus, the lack of host immune cell derived IL-30 may improve the effects of IL-30 silencing in PC-SLCs on tumor growth and host behavior.
To assess the consequences of the lack of host- and PC-SLC- derived IL-30 in tumor progression, we next looked at the development of spontaneous metastases in both WT and IL-30KO mice, bearing IL-30-silenced or control tumors (mice were sacrificed when the primary tumors reached similar average volumes; $795 \mathrm{~mm}^{3}$, ANOVA: $p=0.775049$ ).

Autopsy and histopathological examinations of the different organs (liver, lung and spleen) confirmed that, as observed when orthotopically implanted into the prostate [8], PIN-SCs primarily metastasized to the lungs (Fig. 1F). However, when silenced for IL-30 gene their metastatic capacity was greatly reduced. Indeed, 73\% $(22 / 30)$ of WT mice bearing IL-30shPIN-SC tumors were metastasis-free, whereas only $33 \%(10 / 30)$ of mice bearing wild type PIN-SC- or control shPIN-SC tumors were found metastasis-free at the time when the primary tumor had reached the same volume (Fisher's exact test: $p=0.004$ ) (Fig. 1G). The percentage of metastasis-free mice reached $80 \%(24 / 30)$ in IL-30KO mice bearing IL30 shPIN-SC tumors, whereas only $37 \%$ (11/30) of IL$30 \mathrm{KO}$ mice bearing control tumors were metastasis-free (Fisher's exact test: $p=0.0006$ ) (Fig. 1G). Therefore, lung metastasis is primarily modulated by the inhibition of IL-30 in PC-SLCs than in the host environment.

\section{IL-30-1-tumors display a poor vascularization, frequent apoptotic events associated with a prominent $\mathrm{CD} 4^{+} \mathrm{T}$ cell infiltrate and lack of $\mathrm{CD}_{4}^{+}{ }^{+}$Foxp $3^{+}$Treg cells}

To uncover the mechanisms underlying the slow growth of control tumors in IL-30KO mice and the anti-tumor efficacy of the IL-30 double blockade (in both PC-SLCs and host environment), we first assessed in vivo the tumor viability and immune cell infiltrate.

Although histological aspects of PIN-SC tumors grown in IL-30KO mice were similar to those of PIN-SC tumors developed in WT mice (small epithelioid to round cells, frequent mitosis and a rich vascularity), some apoptotic features emerged (cell shrinkage and nuclear condensation 
and fragmentation). By contrast, $\mathrm{IL}-30^{-/}$tumors, in addition to a worsening of the ischemic-coagulative necrosis, typical of a vascular deficiency, showed frequent apoptotic figures (Fig. 1H).

Immunohistochemistry confirmed the severe impairment $(p<0.01)$ of the vascular supply in IL- $30^{-/}$tumors, which was significantly $(p<0.01)$ reduced compared to the already poor vascularization observed in IL-30-silenced tumors grown in WT mice $(p<0.01)$. Consistently, the vascularization of control tumors was prominent and similar in IL-30KO and WT mice (Table 1 and Fig. 1H).

Both the frequency of Sca-1 positivity, which characterizes the stem phenotype, and of PCNA positivity, which marks proliferation, were substantially $(p<0.01)$ reduced in IL-30-silenced tumors when compared with controls, regardless of whether the tumor hosts were WT or IL30KO (Table 1 and Additional file 2: Figure S1).

Interestingly, the apoptotic events, already evident from the histology, were confirmed by the TUNEL assay, which showed that apoptotic cells were more frequent $(p<0.01)$ in control tumors developed in IL-30KO mice than in those from WT mice. Furthermore, apoptosis was higher in IL$30^{-1-}$ tumors, when compared with control tumors from both IL-30KO and WT mice $(p<0.01)$, but also when compared with IL-30-silenced tumors from WT mice $(p<0.01)$ (Table 1 and Fig. $1 \mathrm{H}$ ), thus, suggesting the involvement of host-derived IL-30 in regulating cancer cell apoptosis, whereas proliferation and stemness remained unaltered.

In the tumor microenvironment (TME), IL-30 expression was evident in cancer cells forming shPIN-SC tumors (in both WT and KO mice), but also in $\mathrm{CD} 11 \mathrm{~b}^{+} \mathrm{Gr}-1^{+}$myeloid-derived cells (MDCs) and macrophages which infiltrated shPIN-SC tumors and, to a lesser extent, IL-30shPIN-SC tumors growing in WT mice, whereas, it was lacking in IL-30-silenced tumors developed IL-30KO mice (Fig. 2A and B).
Analyses of the intra-tumoral inflammatory infiltrate revealed a drastic reduction (ANOVA: $p<0.0001$, Tukey's HSD test: $p<0.01$ ) of $\mathrm{F} 4 / 80^{+}$macrophages and MDCs in IL-30shPIN-SC tumors, both in those grown in WT and in IL-30KO mice compared to control tumors in both strains, whereas the $\mathrm{Ly}-6 \mathrm{G}^{+}$granulocyte content remained substantially unchanged (Fig. 2A, C). The reduced MDC infiltrate was accompanied by an evident decrease in the expression of Indoleamine 2,3-Dioxygenase (IDO) (among the tested immunosuppressive mediators, Arg1, iNOS, NOS2, bFGF) as revealed by double immunostainings (Fig. 2A, D). The number of $\mathrm{NKp} 46^{+}$cells showed only a downward trend in tumors grown in IL-30KO mice, whereas, within the lymphocyte population, $\mathrm{CD} 4^{+}$cells were clearly increased in both control and IL-30-silenced tumors of IL-30KO mice, when compared to tumors of WT mice (ANOVA: $p<0.0001$, Tukey's HSD test: $p<0.01)$. CD $4{ }^{+}$Foxp $3^{+}$Tregs were almost absent in control and IL-30-silenced tumors of IL$30 \mathrm{KO}$ mice, while they were well represented and evenly distributed in both control and IL-30-silenced tumors of WT mice (ANOVA: $p<0.0001$, Tukey's HSD test: $p<0.01$ ) (Fig. 2A, C).

Double immunostainings revealed that in both control and IL-30-silenced tumors developed in WT mice, Foxp $3^{+}$cells co-localized with the expression of immunosuppressive cytokines TGF $\beta$ and IL-10, which was also frequently observed in macrophage-like cells close to Foxp3 ${ }^{+}$cells (Fig. 2E).

These data, which suggested that host-derived IL30 conditions the intra-tumoral content of $\mathrm{CD} 4^{+}$Foxp $3^{+}$Tregs and $\mathrm{CD} 4^{+} \mathrm{T}$ lymphocytes, led our investigation on their arrangement and functional status within the TME, and within the lymphoid tissue of $\mathrm{KO}$ mice.

Table 1 Immunohistochemical features of IL-30-silenced tumors developed in WT and IL-30KO mice

\begin{tabular}{|c|c|c|c|c|c|c|c|c|c|c|c|c|c|}
\hline \multirow[b]{3}{*}{ Microvessel density $^{a}$} & \multicolumn{6}{|c|}{ shPIN-SC } & \multicolumn{6}{|c|}{ IL-30shPIN-SC } & \multirow{3}{*}{$\begin{array}{l}\text { ANOVA } \\
p \text { value }^{b} \\
<0.0001\end{array}$} \\
\hline & \multicolumn{3}{|l|}{$\overline{\text { WT }}$} & \multicolumn{3}{|c|}{ IL-30KO } & \multicolumn{3}{|l|}{$\overline{W T}$} & \multicolumn{3}{|c|}{ IL-30KO } & \\
\hline & 17.0 & \pm & 4.2 & 15.5 & \pm & 4.4 & 7.3 & \pm & $4.0^{d}$ & 3.0 & \pm & $2.3^{c}$ & \\
\hline $\mathrm{Sca}-1^{+}(\%)^{\mathrm{a}}$ & 52.7 & \pm & 9.7 & 48.8 & \pm & 8.3 & 26.5 & \pm & $6.6^{d}$ & 20.3 & \pm & $6.9^{d}$ & $<0.0001$ \\
\hline Proliferation Index $(\%)^{a}$ & 68.9 & \pm & 8.4 & 65.0 & \pm & 7.5 & 35.8 & \pm & $6.0^{d}$ & 36.5 & \pm & $7.0^{d}$ & $<0.0001$ \\
\hline Apoptotic Index (\%) & 5.8 & \pm & 3.0 & 16.9 & \pm & $4.4^{e, f}$ & 10.2 & \pm & 4.7 & 28.2 & \pm & $5.6^{c}$ & $<0.0001$ \\
\hline Caspase-3 (\%) ${ }^{\mathrm{a}}$ & 2.1 & \pm & 1.5 & 14.6 & \pm & $2.5^{e, f}$ & 3.3 & \pm & 1.9 & 21.8 & \pm & $5.0^{c}$ & $<0.0001$ \\
\hline Perforin (\%) ${ }^{a}$ & 2.0 & \pm & 1.9 & 12.3 & \pm & $3.7^{e, f}$ & 2.8 & \pm & 2.1 & 30.0 & \pm & $6.3^{c}$ & $<0.0001$ \\
\hline
\end{tabular}

${ }^{\mathrm{a} M i c r o v e s s e l ~ d e n s i t y ~ a n d ~ t h e ~ p e r c e n t a g e ~ o f ~ i m m u n o s t a i n e d ~ c e l l s ~ w e r e ~ a s s e s s e d ~ b y ~ l i g h t ~ m i c r o s c o p y, ~ a t ~} \times 400$ in an $85431.59 \mu \mathrm{m}^{2}$ field, with Qwin image analysis software (version 2.7). Results are expressed as mean \pm SD of CD31 positive microvessels per field (microvessel density), or mean percentage of positive cells/ number of total cells (Sca-1, PCNA, TUNEL, caspase-3, perforin)

b One-way ANOVA for comparisons between all groups

${ }^{c} p<0.01$ Tukey's HSD test compared with IL-30shPIN-SC in WT mice and control tumors in WT and KO mice

${ }^{d} p<0.01$ Tukey's HSD test compared with control tumors in WT and KO mice

$e_{p}<0.01$ Tukey's HSD test compared with control tumors in WT mice

$f_{p}<0.01$ Tukey's HSD test compared with IL-30shPIN-SC in WT mice 

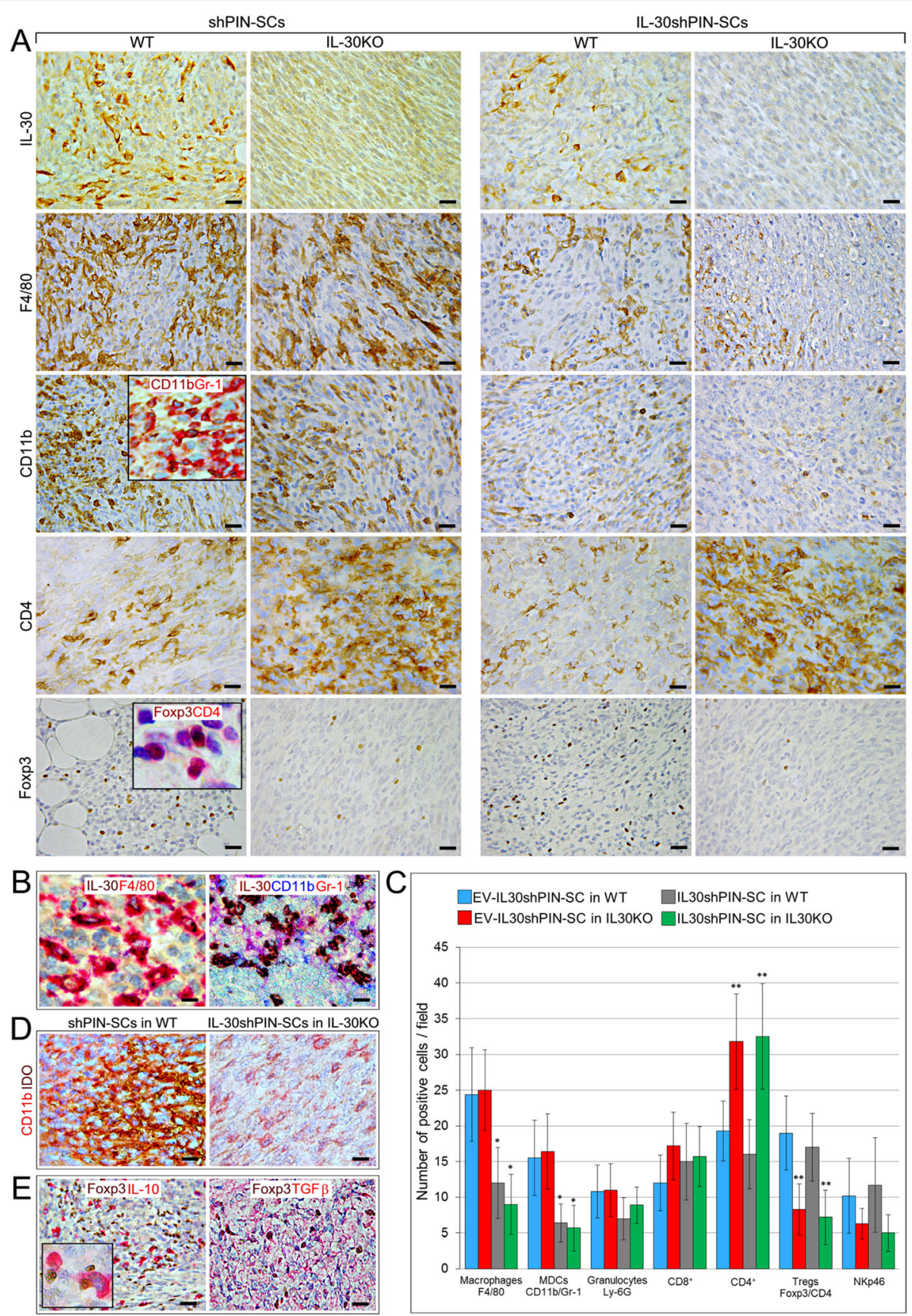

Fig. 2 Immunopathological profile of tumors developed after sC. implantation of IL-30-silenced PIN-SCs in WT and IL-30KO mice. a Immunohistochemical features of IL-30shPIN-SC and shPIN-SC tumors developed in IL-30KO and in WT mice. Magnification: X400. Scale bars: 30 um. The insets show double staining for CD11b (brown) and Gr-1 (red) (X630) and double staining for Foxp3 (brown) and CD4 (red) (X1000). b In shPIN-SC tumors grown in WT mice, double staining reveals that IL-30 (brown) co-localize with F4/80+ macrophages (red), whereas triple staining reveals that IL-30 (brown) also co-localizes with CD11b (blue) and Gr-1 (red), both markers for MDCs. Magnification: × 630. Scale bars: 20 um. c Immune cell counts in IL-30shPIN-SC and control shPIN-SC tumors developed in WT and in IL-30/p28 $8^{\mathrm{f} / \mathrm{f}}$ mice. Results are expressed as mean \pm SD of positive cells/field evaluated at X400 $\left(0.180 \mathrm{~mm}{ }^{2}\right.$ field $)$ by immunohistochemistry. ANOVA: $p<0.01 .{ }^{*} p<0.01$, Tukey HSD Test compared with shPIN-SCs in WT or IL-30KO mice. ${ }^{* *} p<0.01$, Tukey HSD Test compared with shPIN-SCS or IL-30shPIN-SCs in WT mice. $\mathbf{d}$ Double immunostainings of shPIN-SC tumors developed in WT mice and IL-30shPIN-SC tumors developed in IL-30KO mice (IL-30 -/-tumors) reveal a strong expression of IDO (brown), which mostly co-localize with CD11b cells (red), in IL-30//tumors; whereas it is scanty in IL-30/- tumors. Magnification: $\times 630$. Scale bars: $20 \mu \mathrm{m}$. e Double immunostainings of shPIN-SC tumors developed in WT mice reveal that IL-10 and TGF $\beta$ (both in red) mostly co-localize with Foxp3 ${ }^{+}$cells (brown). Magnification: X400. Scale bars: $30 \mu$ m. The inset shows the double staining for Foxp3 (brown) and IL-10 (red): X1000 
$\mathrm{CD}^{+} \mathrm{T}$ lymphocytes, mostly $\mathrm{CD} 4^{+}$, infiltrating IL$30^{-/-}$tumors express cytotoxic molecules and are close to caspase- $3^{+}$apoptotic cancer cells

The defective recruitment of MDCs was the hallmark of IL-30-silenced tumors, regardless of the mouse strain, while the absence of Tregs and the significant $\mathrm{CD} 4^{+} \mathrm{T}$ cell infiltrate, configured all the tumors (control and IL30 -silenced) arising in IL-30KO mice. The apoptotic events, that prevailed in these tumors, were confirmed by immunostainings for activated caspase-3, whose expression is typically associated with cytotoxic $\mathrm{T}$ lymphocyte (CTL)-mediated cytotoxicity [21]. Caspase- $3^{+}$ neoplastic cells were more numerous $(p<0.01)$ in control tumors developed in KO than in WT mice. Furthermore, they were significantly more frequent in IL$30^{-1-}$ tumors compared to control tumors in both $\mathrm{KO}$ and WT mice, and compared to IL-30-silenced tumors in WT mice $(p<0.01)$ (Fig. 3A and Table 1).

The double immunohistochemistry revealed that, in control tumors developed in IL-30KO and, especially, in IL$30^{-/-}$tumors, the caspase- $3^{+}$cancer cells were in close contact with, and frequently embraced by, $\mathrm{CD}^{+} \mathrm{T}$ lymphocytes (Fig. 3B), thus suggesting their cytotoxic effector function. Among these, the $\mathrm{CD}^{+}$cells, which was the prevalent population, mostly expressed the cytotoxic granule-associated RNA binding protein TIA-1 (Fig. 3B).

Assessment of CTL-associated cytotoxic molecules, granzyme B and perforin, revealed that expression, specifically of the latter, was strong in IL- $30^{-/}$tumors, distinct in control tumors grown in KO mice, and absent in IL-30silenced and control tumors grown in WT mice $(p<0.01)$ (Fig. 3A and Table 1). Double stainings also revealed perforin co-localization with $\mathrm{CD}^{+} \mathrm{T}$ cells (Fig. 3A, inset).

Expression of CTL-associated molecules, TNF-related apoptosis-inducing ligand (TRAIL) and FasL, was detected in control tumors grown in IL-30KO mice and, especially, in IL- $30^{-1-}$ tumors, whereas expression of the Fas/ CD95 death receptor concerned most of neoplastic cells, regardless of whether they were silenced or not for IL-30, and regardless of the mouse strain they were implanted in (Fig. 3B, inset), thus suggesting a potential sensitivity of PIN-SC tumors to FasL-mediated apoptosis.

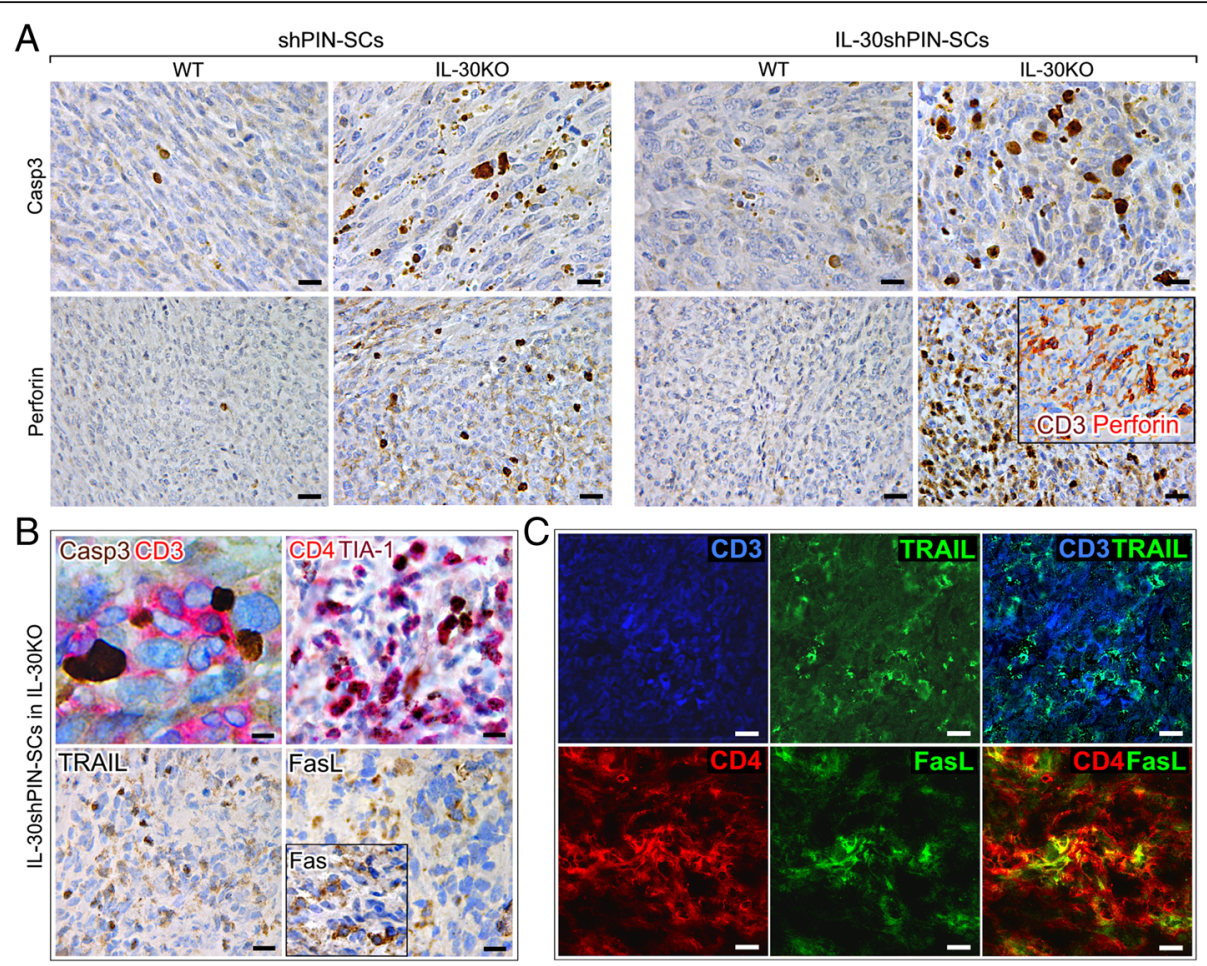

Fig. 3 Immunohistochemical detection of apoptosis-related proteins and CTL cytotoxic molecules in tumors that developed after sc implantation of IL-30-silenced PIN-SCs in IL-30KO mice. a Active caspase-3 and perforin immunostainings in IL-30shPIN-SC and shPIN-SC tumors developed in IL-30KO and in WT mice. Magnification: $\times 630$ (top images) X400 (bottom images). Scale bars: $20 \mu \mathrm{m}$ (top images), $30 \mu \mathrm{m}$ (bottom images). In the inset, the double staining shows perforin (red) co-localization with $\mathrm{CD}^{+}$cells (brown) $(\times 400)$. b Double staining of IL-30 ${ }^{-1-}$ tumors showed $\mathrm{CD}^{+} \mathrm{T}$ cells (red) in close contact with caspase- $3^{+}$neoplastic cells (brown). Magnification: X1000. Scale bar: $10 \mu \mathrm{m}$. Double staining of IL30-/- tumors also shows that CD4 ${ }^{+}$cells (red) mostly express TIA-1 (brown). Immunohistochemical detection of TRAIL, FasL and Fas (inset) in IL$30^{-1-}$ tumors. Magnification: $\times 400$. Scale bars: $30 \mu \mathrm{m}$. c Double immunofluorescent stainings of $\mathrm{LL}-30^{-1-}$ tumors reveal in light blue the colocalization of TRAIL (green) and $\mathrm{CD}^{+}{ }^{+} \mathrm{T}$ cells (blue) and in yellow the co-localization of FasL (green) and $\mathrm{CD} 4^{+} \mathrm{T}$ cells (red). Magnification: X630. Scale bars: $20 \mu \mathrm{m}$ 
Immunofluorescence and confocal analyses revealed that, in tumors grown in IL-30KO mice, many of the $\mathrm{CD}^{+} \mathrm{T}$ cells expressed TRAIL (Fig. 3C) and that FasL expression mostly co-localized with tumor-infiltrating CD4 ${ }^{+}$T cells (Fig.3C).

\section{The spleen of IL-30KO mice lacks the expansion of CD $4^{+} \mathrm{CD} 25^{+}$Foxp $3^{+}$Tregs and expression of IL-10, whereas IFNY and IL-12 expression increases following PC-SLC implantation}

The distinctive features of the immune cell infiltrate of both IL-30-silenced and control tumors developed in IL$30 \mathrm{KO}$ mice, which were enriched with $\mathrm{CD}^{+} \mathrm{T}$ lymphocytes and lacked Tregs, prompted us to characterize the lymphoid tissue in this mouse strain. As expected, the production of IL-30 was missing in the spleen of KO mice, while it was scanty, but detectable, in the reticular framework of marginal zone macrophages and dendritic-like cells in the spleen of WT mice (Additional file 2: Figure S2). IL-30 production appeared substantially unchanged in the spleen of WT mice following tumor cell implantation.

Macroscopic examination of the spleens of IL-30KO mice, revealed that they were more bulky and significantly heavier than spleens of WT mice $(0.12 \pm 0.02 \mathrm{~g}$ versus $0.10 \pm 0.01$ g Student's $t$-test: $p=0.044$ ) (Fig. 4A). A similar difference was also evident in tumor-bearing mice $(0.11 \pm$ $0.01 \mathrm{~g}$ versus $0.08 \pm 0.01 \mathrm{~g}$. Student's $t$-test: $p<0.00001)$.

Flow cytometry analysis showed that the spleens from IL-30KO mice, both the untreated and those bearing tumors, had a greater cellularity than the spleens of WT mice (ANOVA: $p<0.0001$, Tukey's HSD test: $p<0.01$ ) (Fig. 4B), but maintained a similar percentage of $\mathrm{T}$ cell (CD3, CD8a, CD4) and B cell (CD45R) content. After tumor cell implantation, unlike in WT mice, the spleen of IL-30KO mice lacked the expansion of the CD $4{ }^{+} \mathrm{CD} 25^{\text {hi- }}$ Foxp $^{+}$regulatory $\mathrm{T}$ (Treg) cell population (IL-30KO mice: $5.64 \pm 2.23 \%$ versus WT mice: $19.33 \pm 5.60 \%$ of the total number of CD4 ${ }^{+}$cells. ANOVA: $p<0.0001$, Tukey's HSD test: $p<0.01$ ) as shown in Fig. 4 C, D, E.

Immunohistochemistry corroborated the cytofluorimetric data by detecting an expansion of Foxp $3^{+}$cells, mostly distributed in the $\mathrm{T}$ cell areas, in the spleen of tumor-bearing WT mice $(18.8 \pm 4.3 \%)$ versus both healthy WT $(7.1 \pm 4.2 \%)$ and $\mathrm{KO}(7.5 \pm 3.6 \%)$ mice and versus tumor-bearing IL-30KO mice (9.2 $\pm 4.0 \%)$ (Tukey's HSD test: $\mathrm{p}<0.01$ ), regardless of IL-30 silencing in the implanted tumor cells (Fig. 4F).

In WT mice, the Treg cell rich zones showed a distinct expression of IL-10 (Fig. 4F), while IL-12 and IFNy were substantially absent. On the contrary, in the spleen of IL30KO mice bearing IL-30shPIN-SC or shPIN-SC tumors, the network of macrophage- and dendritic-like cells clearly expressed both IL-12 and IFNy (Fig. 4G). Double staining clearly demonstrated IFN $\gamma$ co-localization with F4/80 ${ }^{+}$macrophages and $\mathrm{CD}^{+} \mathrm{T}$ cells (Fig. $4 \mathrm{H}$ ).

\section{IL-30 ${ }^{\text {neg }} \mathrm{PC}$ patients show a significant $\mathrm{CD} 4^{+} \mathrm{T}$ and a poor Foxp $^{+}$cell infiltrate in their surgical samples and have a lower incidence of BCR than IL- $30^{\text {pos }}$ PC patients}

The peculiar immuno-phenotypical profile associated with the drastic growth inhibition of IL-30-silenced tumor in IL-30KO mice (IL-30 ${ }^{-/}$tumors), which survived much longer than WT mice bearing IL-30 expressing tumor (64 versus 36 days, Chi-square test: $p<$ $0.0001)$, prompted us to assess whether it was consistent with the histopathological features of clinical samples and patient outcome.

We previously observed that IL-30 expression typically involved high grade and stage of disease [6], therefore, we analyzed (n.112) PC samples, classified as Gleason score 8 to 10 (high-grade tumors), from patients with stage III disease (high-risk, clinically localized PC), a class of patients whose therapeutic management is still debated and needs to be improved [16]. After staining for IL-30, we applied the evaluation criteria previously described in ref. [6], and selected PC samples with or without IL-30 expression, in both tumor cells and infiltrating leukocytes (ILK) (IL$30^{\text {Pos }}$ PC; n. 25, and IL-30 ${ }^{\text {Neg }}$ PC; n.59, respectively).

Immunohistochemistry revealed that the $\mathrm{CD} 4^{+} \mathrm{T}$ cell infiltrate was considerable $(18.8 \pm 3.1)$ in $\mathrm{IL}-30^{\mathrm{Neg}} \mathrm{PC}$ samples, whereas the Foxp $3^{+}$cell content was scanty to absent $(2.0 \pm 0.8)$ when compared with IL-30 ${ }^{\text {Pos }} \mathrm{PC}$ samples (CD4 ${ }^{+}$cells: $10.20 \pm 2.8$; Foxp $3^{+}$cells: $9.5 \pm 2.9$; Student's t-test: $p<0.001$ ) (Fig. 5A, B). Furthermore, lymphocytes infiltrating IL- $30^{\mathrm{Neg}} \mathrm{PC}$ mostly expressed the activation marker TIA-1 [22] (inset in Fig. 5A).

Kaplan-Meier survival curves showed a significantly shorter Disease-Free Survival for patients with IL- $30^{\mathrm{Pos}} \mathrm{PC}$ (18 out of 25 patients with biochemical recurrence, BCR, $72 \%$ ) versus those with IL-30 ${ }^{\mathrm{Neg}} \mathrm{PC}$ (15 out of 59 patients with BCR, 25\%) (Log-rank test: $p=0.000022$ ) (Fig. 5C).

\section{Discussion}

Despite immunotherapy has revealed to be promising for the treatment of advanced tumors [23], ongoing trials for PC have achieved poor clinical responses [24, 25]. Overcoming immunosuppression generated by the aberrant tumor-host relationship and breaking resistance to current immunotherapeutic strategies is a major challenge for oncology.

In an attempt to define the molecular mediators of the PC - host interactions, we identified the expression of the cytokine IL-30, also known as IL-27p28, which we recently investigated throughout the natural history of prostate cancer [6]. Absent in normal prostatic epithelia, the production of IL-30, which in the early stages of the 

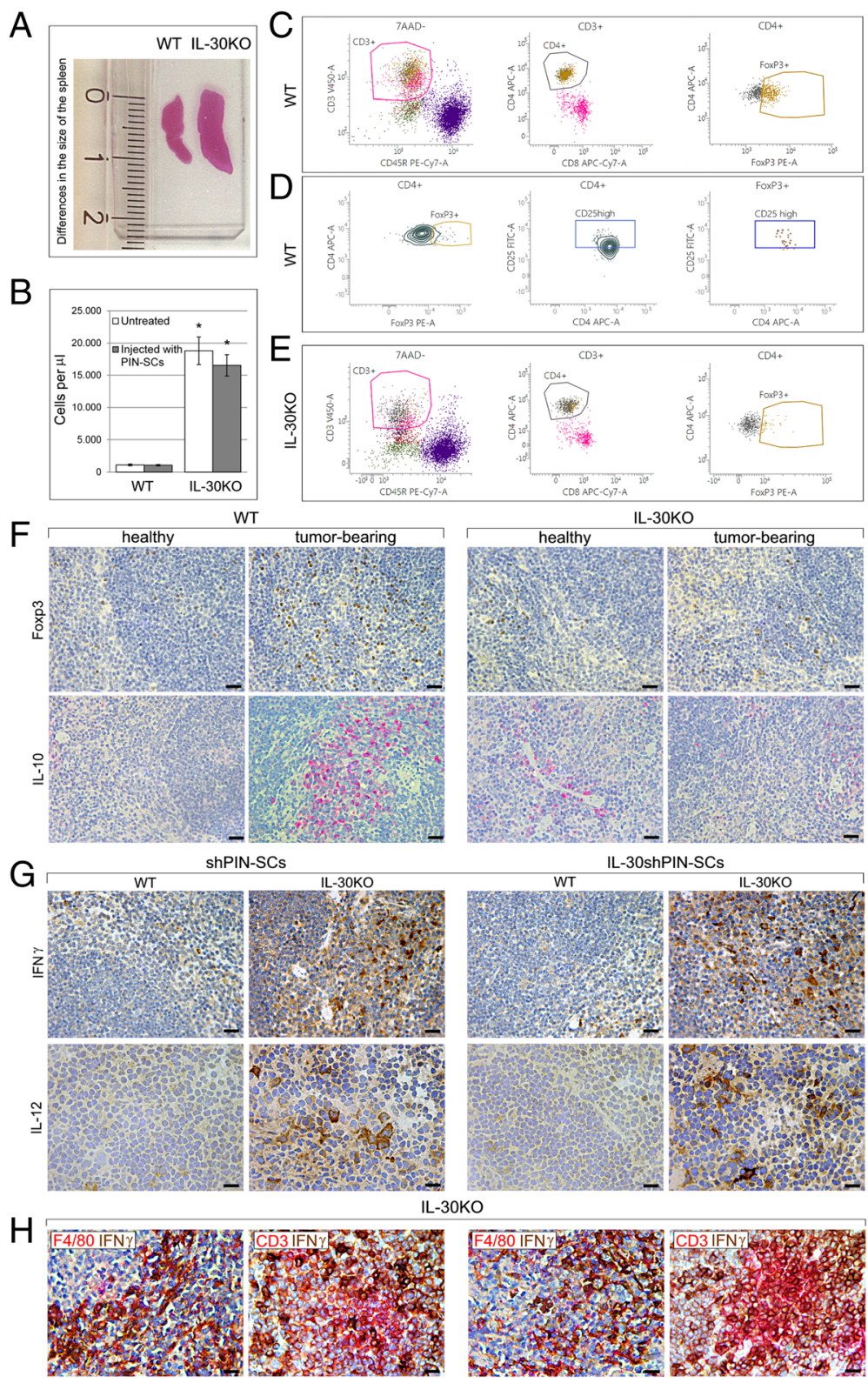

Fig. 4 Histopathological and cytofluorimetric aspects of the spleen of IL-30KO mice. a H\&E stained sections of the spleens obtained from untreated WT and IL-30KO mice showing differences in macroscopic appearance and in size. b Total number of cells in the spleens from WT or IL-30KO mice, injected or not with $1 \times 10^{5}$ PIN-SCs. Results are reported as mean \pm SD of viable cells evaluated by flow cytometry, using 7-aminoactinomycin D (7-AAD) staining. $\mathbf{c}$ and $\mathbf{d}$ illustrate flow cytometry analysis of Treg cells in one representative spleen sample from a WT mouse, injected with PIN-SCS. c. After exclusion of dead cells (7-AAD-positive), CD3 + CD4 + CD45R- nucleated cells were gated and analyzed for Foxp3. d. Most of the $\mathrm{CD}^{+} \mathrm{Foxp3}^{+}$population showed high CD25 expression. Isotype controls were used to assess the background. Experiments were performed at least in triplicate. e Flow cytometry analysis of Tregs in one representative spleen sample from an IL-30KO mouse, injected with PINSCs. After exclusion of dead cells (7-AAD-positive), $\mathrm{CD}^{+} \mathrm{CD}^{+} \mathrm{CD} 4 \mathrm{R}^{-}$nucleated cells were gated and analyzed for Foxp3. Experiments were performed at least in triplicate. $\mathbf{f}$ Immunohistochemical features of spleens obtained from healthy and (PIN-SC) tumor-bearing WT and IL-30KO mice. Results obtained from mice bearing control shPIN-SC tumors are not different from those obtained in mice bearing PIN-SC tumors. Magnification: $\times 400$. Scale bars: $30 \mu \mathrm{m}$. g Immunohistochemical features of spleens obtained from WT and IL-30KO mice bearing shPIN-SC or IL30shPIN-SC tumors. Results obtained from WT and KO mice bearing control shPIN-SC tumors are not different from those obtained in the same mouse strain bearing PIN-SC tumors. Magnification: $\times 400$ (top); $\times 630$ (bottom). Scale bars: $30 \mu \mathrm{m}$ (top); $20 \mu \mathrm{m}$ (bottom). $\mathbf{h}$ Double immunohistochemistry reveals that in the spleen of IL-30KO mice bearing shPIN-SC or IL-30shPIN-SC tumor, IFNy (brown) mostly co-localizes with F4/80 $0^{+}$macrophages (red) and, to a lesser extent with CD3 ${ }^{+} T$ cells (red). Magnification: X400.Scale bars: $30 \mu \mathrm{m}$ 

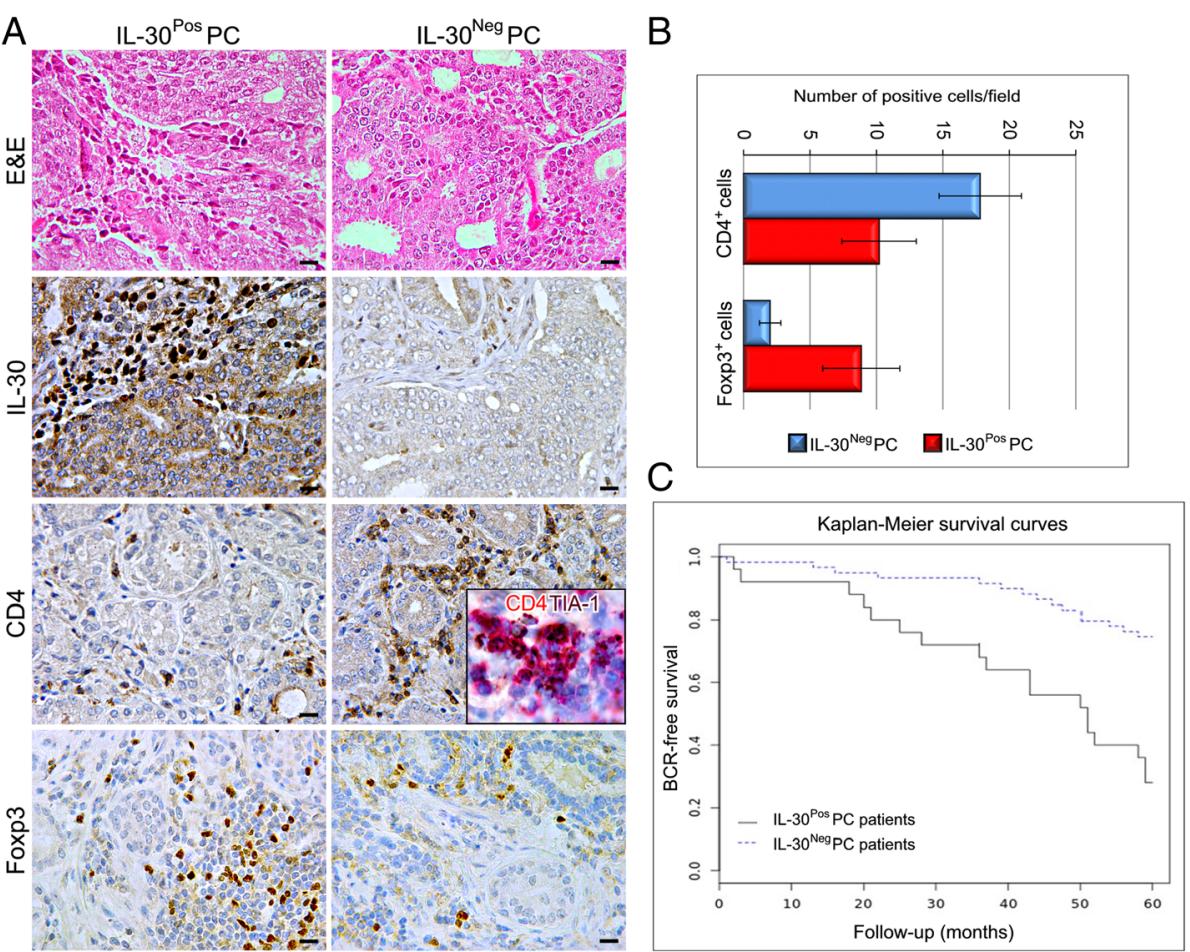

Fig. 5 Immunophenotypical aspects of high grade and stage IL-30 Pos and IL-30 Neg PC and prognostic evaluations. a Histologic (H\&E) and immunohistochemical features of high grade and stage IL-30 NegPC and IL-30 Pos PC. Magnification: X400. Scale bars: $30 \mu \mathrm{m}$. The inset shows TIA-1

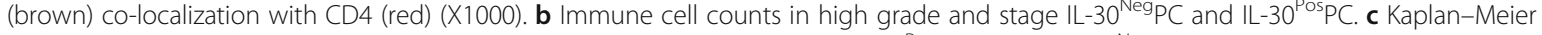

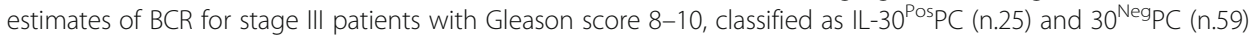

disease is confined to the rare PC-SLCs, typically characterizes the poorly differentiated, high-grade PC, possibly due to the role of this very small cell population as a major component and driver of key processes in cancer progression, such as tumor growth, recurrence and metastasis [26]. Furthermore, tumor infiltrating leukocytes, most of which MDCs, are main source of the cytokine [6]. This occurs primarily in advanced stages of PC [6, 7], which are characterized by intra-tumoral immature MDCs that promote tumor vascularization [27] and suppress DC functions [28] and T cell activation [29, 30].

We have previously shown that IL-30 boosts cancer cell expression of CCL4, CSF-2, CSF-3, CXCL1, CXCL2 and PTGS2, which along with IL-1 $\beta$, IL- 6 and TNF $\alpha$, promotes MDC accumulation and immunosuppressive activity $[8,31]$, whereas IL-30 silencing in PC-SLCs, reduces the tumor infiltration of MDCs, depletes the vascular supply and prevents or delays PC onset and progression [8]. Here, we provide evidence of the synergistic effect of IL-30 knockdown, in both PC-SLCs and host environment, in hampering tumor growth and progression and improving host survival.

Deletion of IL-27p28 alleles makes the IL-27p28 $8^{\mathrm{f} / \mathrm{f}}$ conditional $\mathrm{KO}$ mice, used in our study, unable to produce IL-30, as confirmed by the complete lack of production of the cytokine in the splenic tissue and in the TME.
Mainly produced by activated APCs [3, 32], IL-30 has been recognized as a self-standing cytokine [3], which acts by recruiting a gp130 homodimer and signals via IL-6R $\alpha$ [33]. Alternatively, it may be co-expressed with EBI3 to form the heterodimeric IL-27, which engages the WSX-1/gp130 receptor complex [3], or may combine with cytokine-like factor (CLF) to form a functional complex which, as well as IL-30, has been described to bind to IL-6R $\alpha$ and gp130 [34]. Studies carried out so far, using IL-30KO mice, suggest that the lack of host IL-30 increases the susceptibility to liver injury, by boosting IFN $\gamma$ production by $\mathrm{CD}^{+}{ }^{+} \mathrm{T}$ cells [15], increases the sensitivity to LPS-induced sepsis, through the inhibition of IL-10 and up-regulation of IFN $\gamma$ production by Natural Killer-like T cells [35]. Our results are consistent with previous findings and demonstrate, for the first time, that the lack of leukocyte-derived IL-30 hinders $\mathrm{CD} 4^{+} \mathrm{CD} 25^{+} \mathrm{Foxp}^{+}$Treg expansion and immunosuppressive cytokine production in the lymphoid tissues and in the TME. When combined with IL-30 knockdown in PC-SLCs, it significantly affects tumor growth and host survival.

It should be emphasized that IL-30 silencing in PCSLCs greatly reduces the intra-tumoral recruitment of leukocytes, particularly macrophages and MDCs, which are potential source of IL-30, thus determining a 
reduction of IL-30 within the TME, and mimicking the lack of IL-30-producing leukocytes, which characterize IL-30KO mice.

If the altered immunological equilibrium resulting from the absence of IL-30/IL-27p28 production, can be ascribed to IL-30 in itself or to the coexisting lack of IL-27 or other p28-containing molecular complexes, remains a critical issue.

The lack of host-derived IL-30 not only prevents the pathophysiological expansion of Tregs in the spleen, after PC-SLC engraftment, but also shapes the TME by abolishing the influx of $\mathrm{IL}-10^{+} \mathrm{TGF} \beta^{+}$Tregs, while it promotes that of $\mathrm{CD}^{+} \mathrm{T}$ lymphocytes. The prevention of intra-tumoral immunosuppressive $\mathrm{IDO}^{+} \mathrm{MDC}$ infiltrate, due to IL-30 silencing in PC-SLCs, likely boosts the cytotoxic and tumoricidal activity of $\mathrm{T}$ lymphocytes, as suggested by the frequency of caspase- $3^{+}$apoptotic cancer cells close to $\mathrm{CD}^{+} \mathrm{T}$ lymphocytes, which express cytotoxic molecules perforin, TRAIL or FasL.

Besides improving the efficacy of tumor-reactive $\mathrm{CD} 8^{+} \mathrm{T}$ cells [36, 37], the $\mathrm{CD} 4^{+} \mathrm{T}$ cells have been recognized with a CTL activity in both tumor models [38] and human antitumor responses [39]. Expansion of effector perforin ${ }^{+-}$ FasL ${ }^{+} \mathrm{CD} 4^{+} \mathrm{T}$ cells has been described in cancer patients, during neo-adjuvant chemotherapy, in proportion to clinical response [40]. Besides killing directly MHC class II positive tumor cells, $\mathrm{CD} 4^{+} \mathrm{T}$ lymphocytes can indirectly eliminate cancer cells lacking of MHC class II [38], which is the most frequent condition in tumors, including PC [40], and in our PC-SLCs. These cells are equipped with MHC class I and can express MHC class II, following IFNY treatment [13]. After tumor cell challenge, IL-30 conditional $\mathrm{KO}$ mice showed an imbalance towards a Th1-type immune response, as revealed by IFN $\gamma$ and IL-12 expression in splenic lymphocytes and macrophages. The question of whether these cytokines can promote $\mathrm{CD} 4^{+} \mathrm{CTL}$ activity [41-43] or be involved in the inhibition of tumor angiogenesis [44], remains to be explored. Indeed, in IL- $30^{-/+}$and IL- $30^{-/-}$tumors, the F4/80 macrophage and $\mathrm{IDO}^{+} \mathrm{CD} 11 \mathrm{~b}^{+} \mathrm{Gr}-1^{+}$myeloid cell content was somewhat depleted, which in itself compromises tumor angiogenesis and alleviates suppression of T cell activity [30]. Only in IL-30 $0^{-1-}$ tumors, the significant influx of $\mathrm{CD}_{4}^{+} \mathrm{T}$ cells and the lack of Treg suppressive functions, both dependent on IL-30KO immunophenotype, coexist with the scanty intra-tumoral MDC infiltrate determined by the silencing of IL-30 in PC-SLCs. Killing of PCSLCs by $\mathrm{MHC}$ class I-restricted $\mathrm{CD} 3^{+} \mathrm{CD} 8^{+} \mathrm{T}$ cells, involving TRAIL-mediated apoptosis or perforin-mediated lysis of tumor cells [45], may not be ruled out, although $\mathrm{CD}^{+}{ }^{+} \mathrm{T}$ cells were consistently more represented than $\mathrm{CD}^{+}$cells and were the prevalent immune cell population in tumors grown in IL-30KO mice.

Death ligands TRAIL and FasL belong to a subgroup of the TNF superfamily, which share a TNF homology domain and induce apoptosis by binding, as trimers, to the corresponding death domain containing receptors. TRAIL can bind two apoptosis-inducing receptors TRAIL-R1 (DR4) and TRAIL-R2 (DR5) [46], whereas FasL binds to CD95/Fas receptor expressed by the majority of cancer cells in PIN-SC tumors.

Active caspase-3, which is widely expressed in IL- $30^{-/}$tumors as well as TUNEL-positive staining, is involved in the apoptotic signaling cascades of both TRAIL and FasL [46, 47]. Apoptotic cell death is a hallmark of tumors developing in IL-30KO mice. In IL-30 ${ }^{-1-}$ tumors, apoptotic events occurred together with ischemic-coagulative necrosis associated with an impaired vascularization. Tumor necrosis should release high amounts of tumor-derived antigens to be taken up by APCs and promote $\mathrm{CD} 4^{+} \mathrm{T}$ cell activation and an enhanced antitumor response [48].

The absence of IL-30 in the host environment is not sufficient to prevent metastases, but it improves the protective effect of IL-30 silencing in PC-SLCs increasing the percentage of metastasis-free mice from 73\% (of WT mice bearing IL-30-silenced tumors) to $80 \%$ (of IL-30KO mice bearing IL-30-silenced tumors).

The data from tumor-bearing IL-30KO mice led our immunophenotypical analyses of PC tissues from patients with high-grade, locally advanced disease, for which management guidelines and prognostic criteria are highly debated [16]. We focused on patients bearing $\mathrm{IL}-30^{\mathrm{Pos}}$ or $\mathrm{IL}-30^{\mathrm{Neg}}$ tumors, i.e. with or without IL-30 expression in both cancer and ILK, which mimicked the $\mathrm{IL}-30^{+/+}$tumors grown in wild-type mice, and $\mathrm{IL}-30^{-1-}$ tumors from IL-30KO mice, respectively. As described in murine tumor tissues, in IL- $30^{\mathrm{Neg}} \mathrm{PC}$ samples, the lack of IL-30 in both cancer and infiltrating leukocytes was associated with a scanty to absent Foxp ${ }^{+}$Treg cell content and a distinct TIA$1^{+} \mathrm{CD} 4^{+} \mathrm{T}$ cell infiltrate. By contrast, IL- $30^{\mathrm{Pos}} \mathrm{PC}$ samples were rich in Foxp $3^{+}$Tregs and lacking in $\mathrm{CD} 4^{+} \mathrm{T}$ cells. Most of all, among patients undergoing prostatectomy due to high-grade and locally advanced PC, those with IL- $30^{\mathrm{Neg}}$ cancer showed, as revealed by the Kaplan-Meier curve, a longer disease-free survival, thus suggesting the potential value of translating these research findings to the clinical practice.

\section{Conclusions}

Our data provide the proof of concept that targeting IL30 in both cancer and host environment consistently inhibits tumor growth, ameliorates immune reactivity and reduces the risks of disease recurrence. This study highlights the value of patient-tailored immunotherapy for advanced PC designed to overcome the immunosuppressive PC microenvironment and effectively improve patient outcome. 


\section{Additional files}

Additional file 1: Table S1. Antibodies used in flow cytometry. Table S2. Antibodies used in immunostaining. (DOCX $24 \mathrm{~kb}$ )

Additional file 2: Figure S1. Sca-1 and PCNA immunostainings in shPIN-SC and IL-30shPIN-SC tumors, developed in WT and IL-30KO mice. Figure S2. IL-30 immunostaining in the spleen of WT and IL-30KO mice. (DOCX $775 \mathrm{~kb})$

\section{Abbreviations}

BCR: Biochemical recurrence; Casp3: Caspase-3; CCL: Chemokine (C-C motif) ligand; CSF: Colony-stimulating factor; CXCL: Chemokine (C-X-C motif) ligand; Ella-p28 ${ }^{\mathrm{f} / \mathrm{f}}$ : IL-27p28 conditional knockout mouse strain; IDO: Indoleamine 2,3dioxygenase; IFNY: Interferon gamma; IL: Interleukin; IL-30 ${ }^{+/+}$tumors: PIN-SC or shPIN-SC tumors in WT mice; IL-30"-tumors: IL-30shPIN-SC tumors in IL$30 \mathrm{KO}$ mice; IL-30 ${ }^{+/}$tumors: PIN-SC or shPIN-SC tumors in IL-30KO mice; IL$30^{-/+}$tumors: IL-30shPIN-SC tumors in WT mice; ILK: Infiltrating leukocytes; KO: Knockout; MDCs: Myeloid derived cells; MTV: Mean tumor volume; PC: Prostate cancer; PCNA: Proliferating cell nuclear antigen; PC-

SLCs: Prostate Cancer Stem-Like Cells; PIN-SCs: Prostatic intraepithelial neoplasia-derived stem-like cells; PTGS2: Prostaglandin-endoperoxide synthase 2; Sca-1: Stem cells antigen-1; shRNA: Short hairpin RNA; TIA1: Cytotoxic granule-associated RNA binding protein; TME: Tumor microenvironment; TNF: Tumor necrosis factor; TRAIL: TNF-related apoptosisinducing ligand; Tregs: T regulatory cells; TUNEL: Terminal deoxynucleotidyl transferase dUTP nick end labeling; WT: Wild type

\section{Acknowledgements}

We thank Dr. Paola Siccu for her assistance in performing histology and immunohistochemistry.

\section{Authors' contributions}

EDC designed the study and wrote the manuscript. ZY and LFL generated and provided the p28 conditional knockout mouse model, respectively. CS, SC, and PL performed experiments. MM assisted with the experiments. EDC and CS supervised the study and performed data analysis and interpretation. MB provided the PIN-SCs. All authors read and approved the final manuscript.

\section{Funding}

This work was supported by grants from the Italian Ministry of Health, Ricerca Finalizzata (RF-2013-02357552 to E. Di Carlo).

The funding body had no role in the design of the study and collection, analysis, and interpretation of data and in writing the manuscript.

\section{Availability of data and materials}

The datasets analyzed during the current study are available from the corresponding author on reasonable request.

\section{Ethics approval and consent to participate}

For the study on human prostate samples, written informed consent was obtained from patients. The study was performed in accordance with the principles outlined in the Declaration of Helsinki and approved by the Ethical Committee of the "G. d'Annunzio" University (PROT 1945/09 COET of July 14, 2009). Animal procedures were performed in accordance with the European Community guidelines and were approved by the Institutional Animal Care Committee of "G. d'Annunzio" University and by the Italian Ministry of Health (Authorization n.399/2015 PR).

\section{Consent for publication}

Not applicable.

\section{Competing interests}

The authors declare that they have no competing interests.

\section{Author details}

'Department of Medicine and Sciences of Aging, G. d'Annunzio University of Chieti-Pescara, Via L. Polacchi 11, 66100 Chieti, Italy. ${ }^{2}$ Anatomic Pathology and Immuno-Oncology Unit, Center for Advanced Studies and Technology (CAST), G. d'Annunzio University of Chieti-Pescara, Chieti, Italy. ${ }^{3}$ The First
Affiliated Hospital, Biomedical Translational Research Institute, Guangdong Province Key Laboratory of Molecular Immunology and Antibody Engineering, Jinan University, Guangzhou, China. ${ }^{4}$ Division of Biological Sciences, Center for Microbiome Innovation and Moores Cancer Center, University of California, San Diego, La Jolla, CA, USA. ${ }^{5}$ Cellular Immunology Unit, San Raffaele Scientific Institute, Milan, Italy.

Received: 13 February 2019 Accepted: 8 July 2019

Published online: 31 July 2019

\section{References}

1. Siegel RL, Miller KD, Jemal A. Cancer statistics, 2016. CA Cancer J Clin. 2016; 66:7-30.

2. Torre LA, Siegel RL, Ward EM, Jemal A. Global Cancer incidence and mortality rates and trends--an update. Cancer Epidemiol Biomark Prev. 2016;25:16-27.

3. Pflanz S, Timans JC, Cheung J, Rosales R, Kanzler H, Gilbert J, et al. IL-27, a heterodimeric cytokine composed of EBl3 and p28 protein, induces proliferation of naive CD4(+) T cells. Immunity. 2002;16:779-90.

4. Garbers C, Hermanns HM, Schaper F, Müller-Newen G, Grötzinger J, RoseJohn S, et al. Plasticity and cross-talk of interleukin 6-type cytokines. Cytokine Growth Factor Rev. 2012;23:85-97.

5. Shimozato O, Sato A, Kawamura K, Chiyo M, Ma G, Li Q, et al. The secreted form of p28 subunit of interleukin (IL)-27 inhibits biological functions of IL27 and suppresses anti-allogeneic immune responses. Immunology. 2009; 128:e816-25.

6. Di Meo S, Airoldi I, Sorrentino C, Zorzoli A, Esposito S, Di Carlo E. Interleukin30 expression in prostate cancer and its draining lymph nodes correlates with advanced grade and stage. Clin Cancer Res. 2014;20:585-94.

7. Di Carlo E. Interleukin-30: a novel microenvironmental hallmark of prostate cancer progression. Oncoimmunology. 2014;3:e27618.

8. Sorrentino C, Ciummo SL, Cipollone G, Caputo S, Bellone M, Di Carlo E. Interleukin-30/IL27p28 shapes prostate Cancer stem-like cell behavior and is critical for tumor onset and Metastasization. Cancer Res. 2018:78:2654-68.

9. Airoldi I, Cocco C, Sorrentino C, Angelucci D, Di Meo S, Manzoli L, et al. Interleukin-30 promotes breast Cancer growth and progression. Cancer Res. 2016;76:6218-29.

10. Peitzsch C, Tyutyunnykova A, Pantel K, Dubrovska A. Cancer stem cells: the root of tumor recurrence and metastases. Semin Cancer Biol. 2017;44:10-24.

11. Agliano A, Calvo A, Box C. The challenge of targeting cancer stem cells to halt metastasis. Semin Cancer Biol. 2017:44:25-42.

12. Kaplan-Lefko PJ, Chen TM, Ittmann MM, Barrios RJ, Ayala GE, Huss WJ, et al. Pathobiology of autochthonous prostate cancer in a pre-clinical transgenic mouse model. Prostate. 2003;55:219-37.

13. Jachetti E, Mazzoleni S, Grioni M, Ricupito A, Brambillasca C, Generoso L, et al. Prostate cancer stem cells are targets of both innate and adaptive immunity and elicit tumor-specific immune responses. Oncoimmunology. 2013;2:e24520.

14. Mazzoleni S, Jachetti E, Morosini S, Grioni M, Piras IS, Pala M, et al. Gene signatures distinguish stage-specific prostate cancer stem cells isolated from transgenic adenocarcinoma of the mouse prostate lesions and predict the malignancy of human tumors. Stem Cells Transl Med. 2013;2:678-89.

15. Zhang S, Liang R, Luo W, Liu C, Wu X, Gao Y, et al. High susceptibility to liver injury in IL-27 p28 conditional knockout mice involves intrinsic interferon- $\gamma$ dysregulation of CD4+ T cells. Hepatology. 2013;57:1620-31.

16. Heidenreich A, Bastian PJ, Bellmunt J, Bolla M, Joniau S, van der Kwast T, et al. EAU guidelines on prostate cancer. Part 1: screening, diagnosis, and local treatment with curative intent-update 2013. Eur Urol. 2014:65:124-37.

17. Heidenreich A, Aus G, Bolla M, Joniau S, Matveev VB, Schmid HP, et al. EAU guidelines on prostate cancer. Eur Urol. 2008:53:68-80.

18. Brierley JD, Gospodarowicz MK, Wittekind C. TNM - Classificazione dei tumori maligni, ottava edizione. Milano, Italy: Raffaello Cortina Editore; 2017.

19. Epstein Jl, Allsbrook WC Jr, Amin MB, Egevad LL. ISUP Grading Committee. The 2005 International Society of Urological Pathology (ISUP) Consensus Conference on Gleason Grading of Prostatic Carcinoma. Am J Surg Pathol. 2005:29:1228-42.

20. Sorrentino C, Musiani P, Pompa P, Cipollone G, Di Carlo E. Androgen deprivation boosts prostatic infiltration of cytotoxic and regulatory $T$ lymphocytes and has no effect on disease-free survival in prostate cancer patients. Clin Cancer Res. 2011;17:1571-81.

21. Jerome KR, Sloan DD, Aubert M. Measurement of CTL-induced cytotoxicity: the caspase 3 assay. Apoptosis. 2003;8:563-71. 
22. Tian Q, Streuli M, Saito H, Schlossman SF, Anderson P. A polyadenylate binding protein localized to the granules of cytolytic lymphocytes induces DNA fragmentation in target cells. Cell. 1991;67:629-39.

23. Smyth MJ, Ngiow SF, Ribas A, Teng MW. Combination cancer immunotherapies tailored to the tumour microenvironment. Nat Rev Clin Oncol. 2016;13:143-58.

24. Sunshine J, Taube JM. PD-1/PD-L1 inhibitors. Curr Opin Pharmacol. 2015;23:32-8.

25. Dallos MC, Drake CG. Blocking PD-1/PD-L1 in genitourinary malignancies: to immunity and beyond. Cancer J. 2018;24:20-30.

26. Chang JC. Cancer stem cells: role in tumor growth, recurrence, metastasis, and treatment resistance. Medicine (Baltimore). 2016;95:S20-5.

27. Talmadge JE, Gabrilovich DI. History of myeloid-derived suppressor cells. Nat Rev Cancer. 2013;13:739-52.

28. Gabrilovich DI, Ostrand-Rosenberg S, Bronte V. Coordinated regulation of myeloid cells by tumours. Nat Rev Immunol. 2012;12:253-68.

29. Pal SK, Kortylewski M. Breaking bad habits: targeting MDSCs to alleviate immunosuppression in prostate cancer. Oncoimmunology. 2015;5:e1078060.

30. Veglia F, Perego M, Gabrilovich D. Myeloid-derived suppressor cells coming of age. Nat Immunol. 2018;19:108-19.

31. Parker KH, Beury DW, Ostrand-Rosenberg S. Myeloid-derived suppressor cells: critical cells driving immune suppression in the tumor microenvironment. Adv Cancer Res. 2015:128:95-139.

32. Liu J, Guan X, Ma X. Regulation of IL-27 p28 gene expression in macrophages through MyD88- and interferon-gamma-mediated pathways. J Exp Med. 2007;204:141-52

33. Garbers C, Spudy B, Aparicio-Siegmund S, Waetzig GH, Sommer J, Hölscher C, et al. An interleukin-6 receptor-dependent molecular switch mediates signal transduction of the IL-27 cytokine subunit p28 (IL-30) via a gp130 protein receptor homodimer. J Biol Chem. 2013;288:4346-54.

34. Tormo AJ, Meliani Y, Beaupré LA, Sharma M, Fritz JH, Elson G, et al. The composite cytokine p28/cytokine-like factor 1 sustains B cell proliferation and promotes plasma cell differentiation. J Immunol. 2013;191:1657-65.

35. Yan J, Mitra A, Hu J, Cutrera JJ, Xia X, Doetschman T, et al. Interleukin-30 (IL27p28) alleviates experimental sepsis by modulating cytokine profile in NKT cells. J Hepatol. 2016;64:1128-36.

36. Gao FG, Khammanivong V, Liu WJ, Leggatt GR, Frazer IH, Fernando GJ. Antigen-specific CD4+ T-cell help is required to activate a memory CD8+ T cell to a fully functional tumor killer cell. Cancer Res. 2002;62:6438-41.

37. Antony PA, Piccirillo CA, Akpinarli A, Finkelstein SE, Speiss PJ, Surman DR, et al. CD8+ T cell immunity against a tumor/self-antigen is augmented by CD4+ T helper cells and hindered by naturally occurring $T$ regulatory cells. Immunol. 2005:174:2591-601.

38. Haabeth OA, Tveita AA, Fauskanger M, Schjesvold F, Lorvik KB, Hofgaard PO, et al. How do CD4(+) T cells detect and eliminate tumor cells that either lack or express MHC class II molecules? Front Immunol. 2014;5:174.

39. Péguillet I, Milder M, Louis D, Vincent-Salomon A, Dorval T, PipernoNeumann S, et al. High numbers of differentiated effector CD4 T cells are found in patients with cancer and correlate with clinical response after neoadjuvant therapy of breast cancer. Cancer Res. 2014;74:2204-16.

40. Bander NH, Yao D, Liu H, Chen YT, Steiner M, Zuccaro W, et al. MHC class and II expression in prostate carcinoma and modulation by interferon-alpha and -gamma. Prostate. 1997;33:233-9.

41. Takeuchi A, Saito T. CD4 CTL, a cytotoxic subset of CD4+ T cells. Their Differentiation and Function Front Immunol. 2017;8:194.

42. Corthay A, Skovseth DK, Lundin KU, Røsjø E, Omholt H, Hofgaard PO, et al. Primary antitumor immune response mediated by CD4+ T cells. Immunity. 2005:22:371-83.

43. Haabeth OA, Lorvik KB, Hammarström C, Donaldson IM, Haraldsen G, Bogen $B$, et al. Inflammation driven by tumour-specific Th1 cells protects against Bcell cancer. Nat Commun. 2011;2:240.

44. Sgadari C, Angiolillo AL, Tosato G. Inhibition of angiogenesis by interleukin-12 is mediated by the interferon-inducible protein 10. Blood. 1996;87(9):3877-82.

45. Martínez-Lostao L, Anel A, Pardo J. How do cytotoxic lymphocytes kill Cancer cells? Clin Cancer Res. 2015;21:5047-56.

46. Falschlehner $\mathrm{C}$, Schaefer U, Walczak H. Following TRAlL's path in the immune system. Immunology. 2009;127:145-54.

47. Zheng TS, Schlosser SF, Dao T, Hingorani R, Crispe IN, Boyer JL, et al. Caspase-3 controls both cytoplasmic and nuclear events associated with Fas-mediated apoptosis in vivo. Proc Natl Acad Sci U S A. 1998;95:13618-23.

48. Sancho D, Joffre OP, Keller AM, Rogers NC, Martínez D, Hernanz-Falcón P, et al. Identification of a dendritic cell receptor that couples sensing of necrosis to immunity. Nature. 2009;458:899-03.

\section{Publisher's Note}

Springer Nature remains neutral with regard to jurisdictional claims in published maps and institutional affiliations.
Ready to submit your research? Choose BMC and benefit from:

- fast, convenient online submission

- thorough peer review by experienced researchers in your field

- rapid publication on acceptance

- support for research data, including large and complex data types

- gold Open Access which fosters wider collaboration and increased citations

- maximum visibility for your research: over $100 \mathrm{M}$ website views per year

At BMC, research is always in progress.

Learn more biomedcentral.com/submissions 